\title{
Realization of Digital Production by an ENGINEERING APPLICATIONS-BASED APPROACH
}

\section{COnstantinescu, C. \& Lentes, J.}

Abstract: To cope with the increasing volatility of the markets, companies have to become more flexible and reactive. An approach to enhance the flexibility of industrial companies from the side of technical business processes is Digital Production. The realization of a Digital Production can be done by means of a factory application-based approach to align and optimize the lifecycles of products and factories. The approach envisions that all stakeholders in activities like product design, process development, factory planning as well as production planning and factory operation will be supported by service-based software components, systems or digital tools without creating a single overloaded, hardly manageable system. In this way, the robustness and accuracy of processes will be enhanced and consequently a higher and more stable product and service quality will be achieved and the overall system for product creation will become more flexible and reactive. To bring Digital Production and its application-based realization to live, an innovation cluster was implemented.

Key words: digital production, engineering apps, production process, digital manufacturing
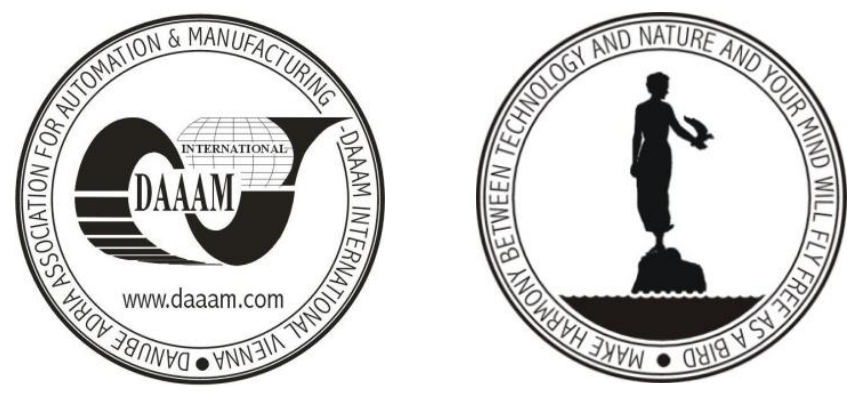

Authors' data: Dr. Constantinescu, C[armen]; Lentes, J[oachim], Fraunhofer Institute for Industrial Engineering IAO, Nobelstrasse 12, 70569, Stuttgart, Germany, Carmen.Constantinescu@iao.fraunhofer.de

This Publication has to be referred as: Constantinescu, C[armen] \& Lentes, J[oachim] (2013) Realization of Digital Production by an Engineering ApplicationsBased Approach, Chapter 23 in DAAAM International Scientific Book 2013, pp. 441-448, B. Katalinic \& Z. Tekic (Eds.), Published by DAAAM International, ISBN 978-3-901509-94-0, ISSN 1726-9687, Vienna, Austria

DOI: $10.2507 /$ daaam.scibook.2013.23 
Constantinescu, C. \& Lentes, J.: Realization of Digital Production by an Engineeri...

\section{Introduction}

Production companies face increasing requirements like decreasing product lifecycles and changing markets. Especially for European production companies, an additional requirement is to cope with the growing competition with companies in lower wage countries, resulting in the need for cost-effective processes and products. But the current proceeding in product generation can be characterized by uncontinuous process chains that are further decelerated by a plurality of time- and cost-intensive coordination activities based on physical prototypes as well as by isolated applications of digital tools. Promising approaches, methods and tools to cope with the requirements on production companies are currently subsumed by the concept Digital Production that is characterised in the following.

\section{Digital Production - Concept Definition}

In the scope of this paper, Digital Production comprises the planning, integration and, operation of product- and production-related processes in industrial enterprises by means of Information Technology (IT). Objective of Digital Production is the advancement of processes in relation to time, costs, and quality and thereby to support the timely development and production of high-quality products in a costeffective manner.

An essential challenge of the realization of Digital Production is the implementation of an integrated process chain from the idea for a product to its production, based on continuous data and information flows as well as workflows. Consequently, starting point for the development of Digital Production are IT-based methods like Digital Mock-up (DMU) and Virtual Reality (VR), Collaborative Engineering, Digital and Virtual Factory as well as an integrated data and lifecycle management not only for products realised as Product Data Management (PDM) and Product Lifecycle Management (PLM), but for factories too. But the current proceeding in product generation can be characterized by uncontinuous process chains that are further decelerated by a plurality of time- and cost-intensive coordination activities based on physical prototypes as well as by isolated applications of digital tools.

The major challenge identified here is represented by the synergizing Manufacturing Engineering (ME) and ICT. Manufacturing Engineering addresses all interrelated aspects of products, processes, factory and production life cycles, from design and engineering to factory operation, and facility management towards recycling/disposal and re-use. Advanced Manufacturing Engineering (aME) is represented by the ICT-centered modeling, simulation, optimization, monitoring and visualization of products, technical processes and factories (Bracht, 2011). The guiding idea of this approach is the alignment of Product and Factory Life Cycles at Factory Level. The Factory Level comprises the following core domains: product design, process development, factory and production planning and factory operation, as illustrated in Figure 1. 


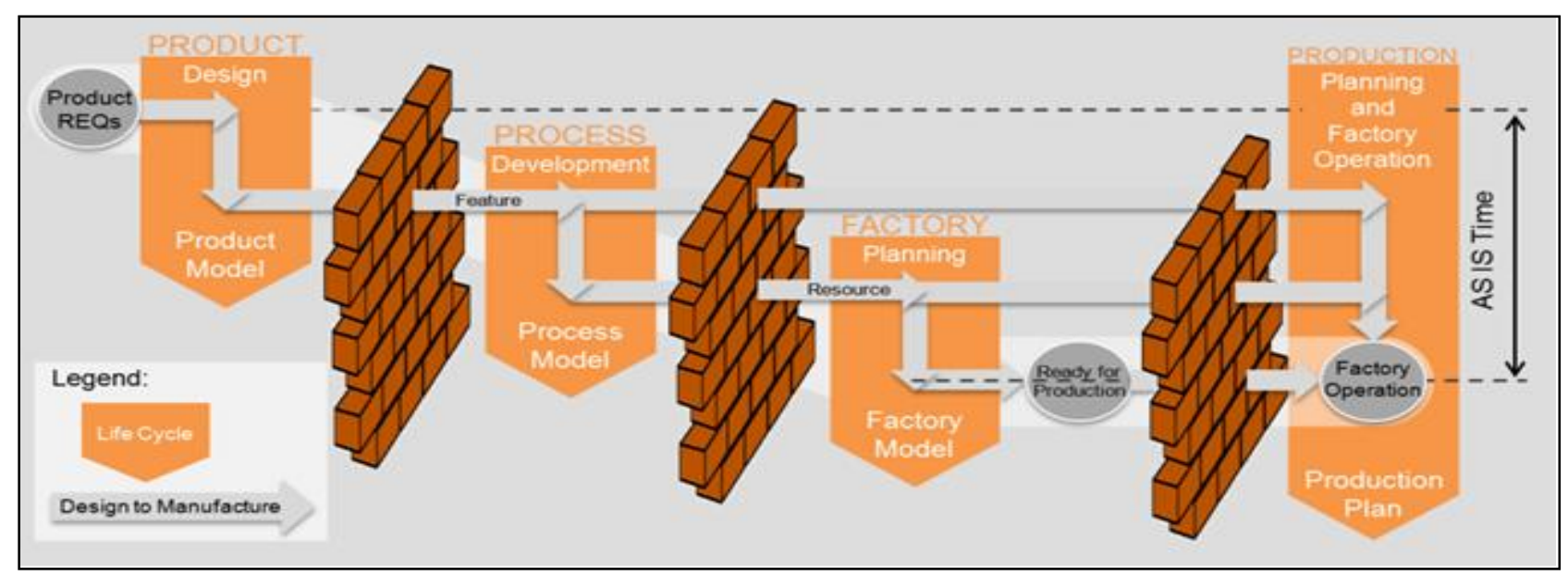

Fig. 1. The challenge of aligning the Product and Factory Life Cycles

Thereby the challenge is the synchronization and simultaneous generation of all these models within the domains by integrating and using/re-using Manufacturing Engineering knowledge in the early stages of the design, planning and monitoring activities. The major challenge here is represented by the serial nature of the product, process and factory decision making along their life cycles. From the product requirements, the product design is generated and stored within a product model (Brown, 2004). Once defined, the process development generates the process requirements (process plan) and the process model from the design features. The factory and production planning domain consists of the selection of the required resources for the factory model and creation of the manufacturing execution programs (Constantinescu et al., 2004) (Constantinescu et al., 2009). After this stage, all the relevant data/knowledge has to be communicated and used for the factory operation (Constantinescu et al., 2005). Therefore, at the factory operation level the Manufacturing Executions Systems (MES) have to be enhanced with simulation capabilities. However, the data and knowledge from the planning domains is not integrated and synchronized with the Enterprise Resource Planning System (ERP) and the MES in the production planning and factory operations domain (Eigner \& Stelzer, 2009).

The life cycle alignment of all Factory Level Domains induces such a complexity that can hardly be handled without the support of ICT technologies. However, the employment of a single holistic manufacturing engineering system seems to be not feasible. But, only the holistic and comprehensive understanding of the Factory Level Domains with all its interrelations enables the task-oriented modularization of complex planning and optimization activities (Landherr, 2011). Based on this the single tasks can be supported by application- and solution-based ICT tools (Landherr et al., 2011). The ICT tools addressing "mission critical" activities have to focus on the required data, information and knowledge supporting processes that are essential for designing the products, developing the processes, planning and operating the production and the factories. Therefore application-based ICT tools and systems, fully enriched with knowledge have to be developed to support these domain specific tasks with respect to the interdependencies between the Factory Level Domains. To develop these ICT tools, complementary to the life cycle orientation, there is a need for a proper interoperability facilitated by standardized interfaces and exchange formats (Lucke et al., 2008, Neumann et al., 2011). 
These aforementioned challenges lead to considerable delays (AS IS Time in Figure 1) between the start of product design (Product Requirements REQs) until the start of production (Ready for Production) due to the following: 1) Separated ways of thinking and domain specific paradigms along life cycles of the Factory Level Domains; 2) Information regarding product design, process development, factory and production planning as well as factory operation are then propagated in specific and isolated "island" application systems. 3) Missing sufficient ICT support for the communication between the domains (Pahl et al., 2007).

The focused motivation of this alignment process is to triple the speed of Factory Level Domain activities along their life cycles from the design and planning levels to the operation level by knowledge-based and simultaneous execution of the activities for Design to Manufacturing. This will be achieved through a common and comprehensive understanding of the Factory Level Domains and strongly supported by employing emerging ICT technologies.

\section{Engineering Apps approach}

This approach will support Manufacturing Engineering (ME) stakeholders (e.g. product designer, factory planner, production planner, factory operator ...) with suchcalled Engineering Apps to enable an integrated product design, process development, factory and production planning and factory operation. This integration is flexible and is achieved through the deployment of a life cycle-oriented platform, based on a core Reference Model for the holistic planning and optimization of products, processes and factories along their aligned life cycles (Porter, 1998).

An Engineering App, further on called eApp, is a high performance piece of software, an application, a system or a digital tool, which supports the product designers, process planners, factory and production planners, factory operators and shop floor managers in their daily activities with a special focus on supporting collaboration. eApps are standard-based and intuitive to use. Additionally they can be characterized by being adaptable, context-aware, pro-active and/or interconnect able. The main purpose of the eApps (e.g. product design, energy consumption monitoring, tendering ...) can be enriched by manufacturing knowledge. These eApps allow the capturing, modeling, representation and sharing of knowledge in all phases of Manufacturing Engineering. They support the re-use of manufacturing knowledge in early phases and the sharing of the manufacturing knowledge between these activities. They cover a complexity range from very simple (e.g. Documentation, User Guides, Mobile KPI Tracking ...) to medium (e.g. process planning, energy monitoring, Mobile Warehouse Picking ...) to very complex (e.g. coupled Discrete Event with Numerical Simulation, System Dynamics, Mobile Manufacturing). They can be deployed (online or offline) on several devices like tablets, smart phones, PCs, Cloud, Grid, and High Performance Computer Clusters".

The characteristics of the eApps are defined as follows: Standard-based: The development of eApps will be based on existing well-established standards and exchange formats, to enable an efficient integration and deployment of the developed eApps in existing manufacturing engineering environments. Intuitive: Easy to use under consideration and application of existing and familiar user interfaces. Adaptable: Role-based customizability of user interfaces. Context-aware: 
Consideration of engineering (e.g. related design and planning activities for dynamic workflow creation) and operation context (e.g. position and condition of manufacturing resources for efficient factory operation). Pro-active: Autonomous generation of recommendations (decision support) for automatic or manual improvements in manufacturing engineering and operation, based on captured, modelled and stored knowledge. Interconnect able: Flexible integration and communication between eApps by facilitating product and factory life cycle management concepts and federative data management concepts (Pahl et al., 2007, Schenk et al., 2010).

Currently available applications and systems support different phases of all these life cycles in an isolated manner, they do not have the capability to be fully and continuously integrated, based on standardized interfaces, in a heterogeneous factory IT landscape (Schuh, 2010). As a consequence, there are communication walls between product designers, factory planners, production planners and factory operators. To overcome the mentioned challenges, this approach aims at the development and flexible integration of three different classes of eApps. On the one hand, these eApps can be deployed and used not only on new devices like smart phones or tablets, where workers can use mobile solution for decision making on the shop floor in the production and operation phase. This is one key element to support workers directly and to increase the efficiency in the production planning and factory operation by inherent collaboration enabled at the usage time. On the other hand they can be deployed on conventional devices like PCs, High Performance Computers etc. to reach a maximum impact in the Manufacturing Engineering world. Thereby, the eApps should not only fulfil their purpose in the production phase, but also actively support the propagation of information in the product, process and factory planning phases. In this approach the flexible integration of the envisioned eApps is realized through modern integration technologies, such as life cycle oriented platforms like Cloud and Grid (Pahl et al., 2007, VFF, 2010).

\section{Implementation under the Innovation Cluster Digital Production, in Germany, at Fraunhofer IAO}

In the scope of this paper, we refer to a cluster in accordance to Porter as "a geographically proximate group of interconnected companies and associated institutions in a particular field, linked by commonalities and complementarities" (Zelm et al., 1999).

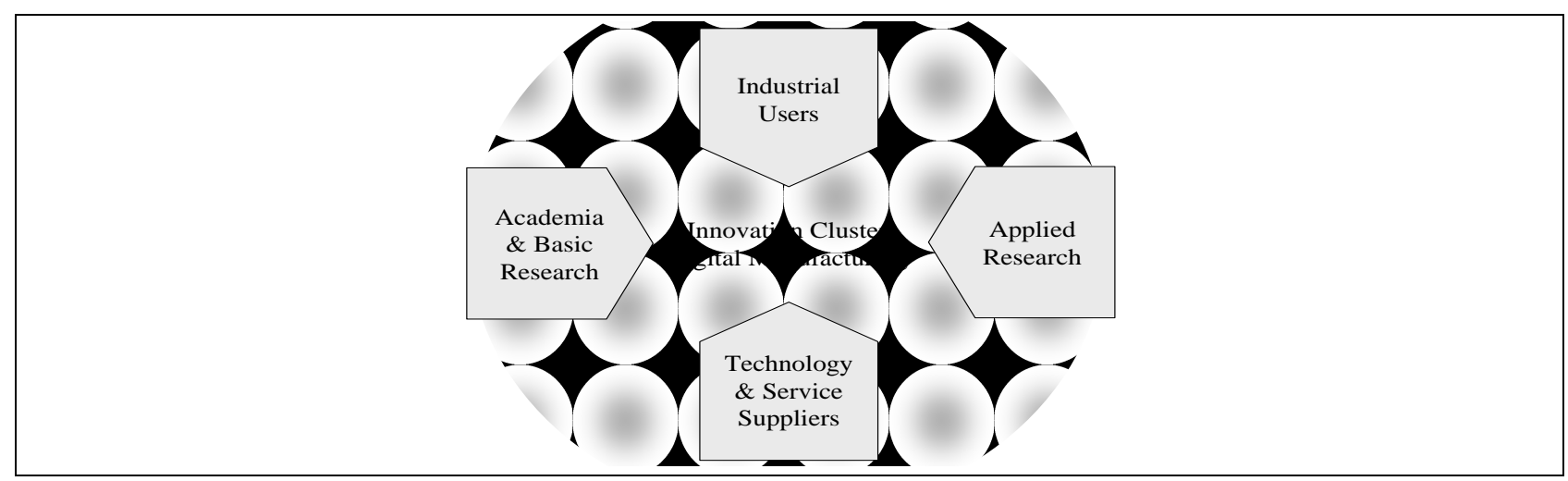

Fig. 2. Initial consortium of the cluster 
The complementary core participants of the cluster with its focus on innovation in and by Digital Manufacturing derive from user companies, technology and service suppliers as well as knowledge providers like research and academia as shown in 0 .

This initial consortium, which is involved during the establishment of the innovation cluster, is enlarged during the ramp-up of the cluster. Supplementary partners will consist in component suppliers of the included industrial users that are mainly end-product companies, thereby widening the perspective of the cluster towards supply and value networks. Furthermore, multipliers like associations and standard-setting agencies will be incorporated to broad the impact that is generated by the innovation cluster. Moreover, it is assumed that the innovation cluster will result in specialized spin-off companies that enlarge the cluster too. Besides this growth in partnership, further support by means of additional grants via regional development programs and research framework programs is envisaged. The overall partnership in the mature cluster is illustrated in 0 .

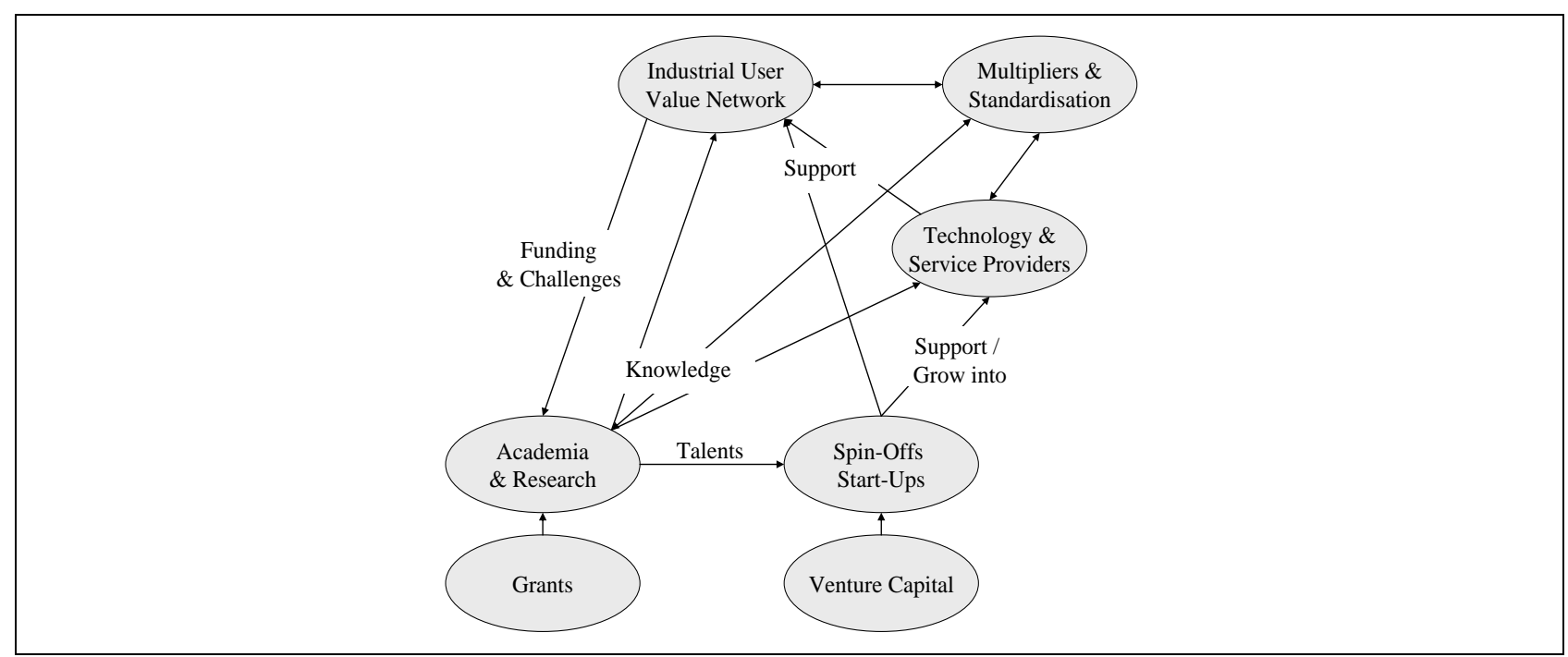

Fig. 3. Partnership in the mature cluster

As shown in Figure 3, the innovation cluster Digital Manufacturing is structured in five generic thematic areas that were developed in a top-down manner, leading to a subdivision in three application-oriented areas and two support-oriented fields. The application oriented areas focus on products, production and enterprise networks, whereby the support-oriented fields address information technology and tools as well as management strategies, methods, and instruments, respectively.

The field Intelligent Products tackles assistance and production systems that support the individualisation of products, which leads to a continuous increase of the complexity of products and processes.

To enhance Production in Digital Manufacturing, in the respective thematic field, adaptive technologies for quality- and performance-optimised manufacturing and assembly are developed.

The cooperation of enterprises in versatile networks, as a purposeful reaction to the ongoing globalisation and concentration tendencies, is addressed by research targeting tools supporting cooperation in development and production. 
Information technology is the key enabler for Digital Manufacturing; therefore the innovation cluster will not only provide new functional modules and their integration into comprehensive systems, but furthermore facilitate their application in the daily work in industry, especially in small and medium-sized enterprises.

Besides the technology-oriented work, one thematic field of the cluster is dedicated to management by strategies, methods and instruments to support best-inclass production using Digital Manufacturing.

Technical results of the innovation cluster will consist in an advancement of Digital Production by new and enhanced functional modules as well as by an improved flow of data and information between the separate building blocks of Digital Production, especially by means of the app-based approach presented in this paper.

Besides the technical advancements of Digital Manufacturing, the innovation cluster will enhance the competitiveness of the involved industrial user companies and their technology and service suppliers, whose product portfolio will be enhanced and extended, too. Academia and research gain knowledge and experience that will be transferred into new curricula and training courses as well as into new research and development activities.

\section{Conclusion}

The alignment of product and factory life cycles through the development and implementation of the such-called engineering Apps, which are flexibly integrated in an federative environment promise the following benefits. Firstly, a major push in the existing technologies for aME beyond the current state-of-the-art, which will allow changes to be made at early design and planning phases of product and corresponding manufacturing processes as well as of all factory structures.

Secondly, knowledge-based paradigms for engineering, design, planning and operation of factories and products offered to the European scientific community. Additionally, this will support the realisation and implementation of the paradigm shift "from competing by reducing costs to competing by high value adding and knowledge-based Manufacturing Engineering". These achievements will be possible through: a) new methods and tools that enable an optimisation of process chains in the design, planning and operation phases for products and factories in order to achieve first-time-right and robust processes; b) Reliable methods and knowledgebased tools to develop simulation models of complex products faster and more intuitively as well as tools integrated in the information and execution system for production optimisation, c) mobile applications to increase the efficiency in the production planning and factory operation by inherent collaboration enabled at the usage time, d) Standardised knowledge models, planning methods, template libraries, collaboration scenarios and knowledge-enriched applications (e.g. applications capable to capture, share and re-use the knowledge).

An innovation cluster was established to advance Digital Production and to bring realisations like the engineering apps to live. Essential partners of the cluster are industry, technology and service providers as well as academia and research. It is 
Constantinescu, C. \& Lentes, J.: Realization of Digital Production by an Engineeri...

the purpose of the innovation cluster to act as a seed crystal for a long-term initiative to substantially advance the domain Digital Production.

\section{References}

Bracht U.; Geckler D.; Wenzel S.: Digitale Fabrik. Methoden und Praxisbeispiele. (Digital Factory. Methods and Practice ), Berlin: Springer; 2011

Brown, AB.: A best practice approach for automating IT management process. IBM: Research Division; 2004

Constantinescu, C., Dürr, M., Decker, F., Westkämper, E.: Virtual Environment for Collaborative Factory Planning. 40th CIRP IMS Conference, 2007

Constantinescu, C.; Eichelberger, H.; Westkämper, E.: Durchgängige und integrierte Fabrik- und Prozessplanung(Comprehensive and integrated factory and process planning): "Grid Engineering for Manufacturing". wt Werkstattstechnik online 2009;993:92-98

Constantinescu, C.; Hummel, V.; Westkämper, E.: The Migration of the Life Cycle Paradigm into the Manufacturing Engineering. Institut für Industrielle Fertigung und Fabrikbetrieb (Institute of Industrial Manufacturing and Management ) 2005

Eigner, M.; Stelzer, R.: Product Lifecycle Management - Ein Leitfaden für Product Development und Life Cycle Management, Berlin: Springer; 2009

Landherr, M.; Constantinescu, C.: Configuration of Factories and Technical Processes: Which Role Plays Knowledge Modelling? Proceedings of the 44th CIRP 2011:1-4

Landherr, M.; Constantinescu, C.: Digital Factory in a Cloud and Grid Environment. ManuFuture Conference 201 1, Wroczlaw, Poland

Lucke, D.; Constaninescu, C.; Westkämper, E.: Smart Factory A Step towards the Next Generation of Manufacturing. Proceedings of the 41st CIRP Conference on Manufacturing Systems 2008:115-118

Neumann, M.; Constantinescu, C.; Westkämper, E.: A Method for Multi-Scale Modeling of Production Systems. Proceedings of the 4th International Conference on Changeable Manufacturing systems, 2011:471-476

Pahl, G.; Beitz, W.; Feldhusen, J.; Grote, KH.: Konstruktionslehre - Grundlagen erfolgreicher Produktentwicklung Methoden und Anwendung.( Engineering Design Basics of successful product development methods and application) Berlin: Springer; 2007

Porter, M.: Clusters and Competition: New Agenda for Companies, Governments and Institutions. Harvard Business School Press, Harvard, 1998

Schenk, M.; Wirth, S.; Müller, E.: Factory Planning Manual. Berlin: Springer; 2010.

Schuh, G.; Eversheim, W.: Integrierte Produkt- und Prozessgestaltung. Berlin: Springer; 2005

VFF NMP-4. (2010): Virtual Framework Factory: Project co-funded by the European Commission within the Seventh Framework Project, D2.1

Zelm,. M; Kosanke, K; Vernadat, F.: CIMOSA: Enterprise engineering and integration. Computers in Industry 1999; 402:83-9 